\title{
Hybrid Activist Collectives: Reframing mothers’ environmental and caring labour.
}

Kelly Dombroski, University of Canterbury.

Kelly Dombroski , (2016)," Hybrid activist collectives: reframing mothers' environmental and caring labour ", International Journal of Sociology and Social Policy, Vol. 36 Iss 9/10 pp. 629 - 646 Permanent link to this document:

http://dx.doi.org/10.1108/IJSSP-12-2015-0150

\section{Introduction}

It was not so long ago that feminist activists of the second wave gathered behind the slogan 'the personal is political' and embraced a politics of ubiquity that recognized the power of women acting in multiple yet particular places (Gibson-Graham, 2005). While forms of organized activism certainly played an important role as well, the widespread and contemporaneous nature of the second-wave feminist revolution resulted primarily from forms of geographically dispersed global activism conducted without coherent central organization. This politics of ubiquity relied on the fact that because women are everywhere, a woman is always somewhere, and in these ‘somewheres' gender relations could be renegotiated (Gibson-Graham, 2005). Two important sites of renegotiation were 'the places closest in’ (Underhill-Sem, 2005): the body and the home. In particular, feminists reframed and challenged naturalised understandings of the reproductive and nurturing capacities of women's bodies, and the domestic sphere as a women's natural place of work and responsibility. While feminist activism is still current and important in these two sites, in this paper I am interested in extending our reframing of women's embodied and homebased caring labour with reference to environmental as well as social activism. In other words, activism for, and with, the 'more-than-human' (Whatmore, 2006).

Firstly, though, what do I mean by activism? I am inclined to take the simple definition of activism, that is, a form of direct action for or against some kind of change, what Blomley refers to as 'progressive struggles' (Blomley, 1994). In the case of environmental activism, I am referring to direct actions on the part of individuals and collectives to actively improve humanenvironment relations. You will note that there is no requirement here to consider oneself as an activist, or to belong to any kind of organisation, or to take any 'militant' action - or even to be human. I am supported here by research with activists - Chatterton and Pickerill’s (2010) research with activists in social centres in the UK, for example, found that they 'articulated their engagement in political projects through messy, complex and multiple identities - always in the process of becoming and moving forward through experimentation and negotiation' (2010, p. 
479). In fact, Chatterton and Pickerill's participants expressed strong desires to 'reject simple divides between activists and their other — the non-militant, ordinary citizen’ (2010, p. 479) and even go so far as to claim 'we are not activists'. They attempt to transform activism into 'a more accessible set of practices and politics’ (2010, p. 480). Despite this reframing of activism away from the militant revolutionary subject, whose identity comes primarily through opposition to oppression or a 'politics of demand' (Day, 2004), activists do still cohere in groups around loose sets of principles or ideals which are acted upon - a kind of 'politics of the act' (Day, 2004). It is the 'politics of the act' that Gibson-Graham, Cameron and Healy are interested in when examine a series of case studies of direct action for economic change in their book Take Back the Economy (2013). In these case studies, individuals, groups, communities, organisations, businesses, indigenous peoples, families - even ecosystems and technologies - are all actively negotiating around six identifiable ethical action points: surviving well, distributing surplus, encountering others, consuming sustainably, caring for commons, and investing in future generations (2013, p. xviii).

What these authors highlight is the growing sense that activism is less about a particular political identity and more about a diverse set of everyday practices of direct action. In this paper, I take on the approach of 'everyday activism' (Chatterton and Pickerill, 2010) and apply it to the direct actions of mothers and others taking direct action for change around the issue of sustainable infant hygiene. Through a case study of an online support group for families practicing nappy (diaper)-free infant hygiene (also known as ‘elimination communication’ (EC)) [1], I argue that the direct actions of members of this 'hybrid' collective are a form of environmental and social activism aimed at transforming the embodied hygiene habits of the next generation, as well as the direct environmental impact of families with infants. In the webgroup 'Oznappyfree', an everyday set of activist practices were enabled by the agentic materialities of communication technology and include a form of 'hybrid' (Whatmore, 2002), crowd-sourced research and activism 'in the wild' (Callon and Rabeharisoa, 2003). In this paper, I put these concepts to use to coin the term 'hybrid activist collective', useful in detecting and naming a form of collectivised — yet essentially unorganised — direct action for better worlds.

But first, let us introduce the practice of elimination communication (EC), unfamiliar to many. In what follows, I set the scene with a composite reconstruction of several focus groups and email posts, evoking the ways in which EC is discussed by some of the mothers involved in this study. I then go on to more conventional means of examining the practice, alongside Community Economies Collective approaches to activism, feminist approaches to women's caring labour, and 
science and technology studies (STS) approaches to hybridity, agency and collectivity.

\section{Elimination communication and OZNappyfree}

Under a large tree in the botanical gardens, a cluster of mothers and small children gather around a few picnic rugs and prams. One mother stands swaying back and forth as she talks, rocking a five-month-old baby in a cloth sling. The baby sits upright over her hip and stares wide-eyed at the crowd of children, babies and mothers. The baby looks up at the mother, then tries to straighten its legs in the sling. "Hang on a minute," she says to the group, and looks around the park as she loosens the rings on the sling. She lifts the baby up and out, and swings it around so that its back is against her front torso, and her hands support its thighs in a loose squat. We now see it is a boy, because in what seemed like one fluid movement she had also removed his nappy. She walks to a nearby bush a little distance from the group, and squats herself, holding him out in front. "Ssssss," she softly cues, and a small stream of urine arcs through the air.

A nearby woman, heavily pregnant and seated cross-legged on a rug, nudges her friend and points.

"What happens if he needs to poo?" she asks with genuine curiosity — she has come here to learn about this “elimination communication” practice after all.

"Oh," the mother answers, "he's gone already this morning, it's normally fine this time of day." She lays the child on the picnic blanket and puts the dry nappy back on. "I have been caught out before, though he normally grunts first and I have time to move him somewhere more appropriate."

“Can't you just let him go over a toilet?” the pregnant woman's friend asks.

"Well, sometimes," the mother replies as she manoeuvres the baby back into the sling. "But I find that public toilets are a bit frightening for them at this age, especially with those new tensecond hand-dryers! He's much more likely to relax and go outside." “Do you ever get people commenting?” The pregnant woman asks, “I mean, I just joined the list so I haven't seen much of what people have written yet. It all just blows my mind, but I can imagine my mother-in-law having something to say!" She rolls her eyes at her friend.

Another mother overhears the conversation and moves over. "People can be pretty sceptical, until they see it for real," she says, “my Maternal and Child Health Nurse told me it was just parent-training or timing, until I cued my daughter to pee in the sink before she had to do a nudeweigh-in!”

"My grandmother told me she used to do something similar with her kids," a mother calls from 
nearby as she follows a newly-walking toddler closely. "She thinks it's kind of an obvious way to reduce the washing - or save money on disposable nappies. Her neighbours have to put their dirty nappies in her bin on rubbish day, because they have two kids in 'sposies and literally can't fit a week's worth in their own bin!”

A third mother chimes in, "Well, I was called a disgusting fat slag by an old guy when I took my son in the gutter near the bowling club. I thought it was pretty rich considering the roundup he had been spraying at the club." She gestures towards a folding potty with a plastic bag insert set up near her pram. "Now I bring this with me, if I remember. I don't want my kids in the middle of that kind of fight."

"Oh, was that you! ?” the first mother exclaims, "I saw that post! What a moron."

The conversation continues as the women try to work out who is who, mentally linking email addresses and sign-in names with real life faces at this irregular regional meet-up of the Oznappyfree online forum for parents practicing elimination communication.

Variously referred to as 'infant pottying', 'natural infant hygiene’, 'diaper/nappy-free babies', 'early toileting' and 'elimination communication', the practice of holding out babies to eliminate their waste has gained increasing interest in Western nations in the last decade or so. The Sydney Morning Herald has ran two full-length articles on the practice (Dunn, 2011; Woodford 2006) and The New York Times has had three (Hartocollis, 2013; Kelley, 2005; Small, 2005). Popular Australian and New Zealand current affairs programme 60 Minutes has run segments on elimination communication, and public libraries in the English-speaking world may contain a small number of popular books dealing with the practice (Bauer, 2006; Boucke, 2008; Gross-Loh, 2009; Hopgood, 2012). The minutes of a local council waste committee in Sydney, Australia even recorded a resolution to investigate the practice as a possible strategy for reducing the amount of disposable nappies ending up in landfill. And of course, like almost anything parenting-related in our time, there are countless websites and blogs sharing the knowledge for free, alongside eBooks and eShops which try to make money from selling the method in pdf form alongside associated products such as split-crotch pants, tiny undies and potties. In recent years, Facebook groups have popped up.

Preceding all this, however, were the forums and email lists of the early 2000s. In March 2000, the Yahoo! group Elimination Communication was set up primarily as an email list to discuss the practice of elimination communication (although as with all Yahoo! hosted groups the messages could be accessed via the online forum view). By 2004, an offshoot group for Australians and New Zealanders was set up by an Australian IT professional and mother of two. 
Known as Oznappyfree, this list primarily served as a more situated space for people to ask questions and get information for geographically and culturally specific issues (where to get a potty, what to dress your child in, what the law says around public toileting of children), as well as have seasonal trends in topic match the seasons of the Southern Hemisphere. By the time I came to do my virtual ethnography in 2009, the group had 453 members, although some were more 'lurkers' than 'posters'. [2] Almost all of the posts are written by mothers, although a number sign off with both parents and the children's names. In 2009 there was one direct post from a father, and one indirect post where a mother-member typed something the father wanted to tell the group. I collected a year of posts in 2009 for more detailed content analysis, and participated in the forum as a mother for some nine years on and off between 2006 and 2015, while 'ECing' my own three children. In 2015, I requested via the forum for long term members (who participated in the 2009 research) to write me short reflections on their EC and other hygiene practices since the first period of formal research.[3] While not all Australian and New Zealand-based 'ECers' are members of this group - notably absent are mothers from cultural backgrounds where forms of EC are already the norm [4] - I argue that the forum as an extended material and social collective plays an active role in re-habituating families into a different form of engagement with bodies, hygiene and space.

\section{Everyday activism and mothers' caring labour}

To what degree can mothers and others engaged in this form of infant hygiene be understood as environmental activists? Elsewhere, the work mothers do to secure organic food for themselves and their children has been critically analysed as individualising 'identity work', constructing a neoliberal consumer fantasy of the 'organic child' who is the sole responsibility of the mother (Cairns, Johnston and MacKendrick, 2013). Likewise, the work American La Leche League mothers do to collectively support each other in breastfeeding their infants and children has been critiqued for its middle-class roots and normative assumptions about women's paid and unpaid work (Bobel, 2001). Yet undoubtedly organic foods and breastfeeding are steps in the direction of environmental sustainability — why are those women not generally understood as environmental activists of everyday practice? Perhaps what we are coming up against here is the traditional analysis of the Left that links activism with more public, demand-based activism, what Chatterton and Pickerill term 'the militant activist'. Post-structural commentators argue that this affective attachment to the 'hegemony of hegemony' (Day, 2004) prevents Leftist academics from seeing the diversity of activist engagements already happening in place (Gibson-Graham, 1996), and is perhaps a form of academic paranoia (Sedgwick, 1997). For those using the 'strong 
theories' (Sedgwick, 2003) of the critical Left, any direct action for change that is too domestic and unorganised seems to smack of the private sphere, and thus, the problematic neoliberal trend of outsourcing caring labour to the ‘shock absorbers’ (MacGregor, 2006) of society — women.

Macgregor’s (2006) sustained argument against ecofeminist essentialism would certainly seem to caution us against unproblematically celebrating the environmental caring work that mothers might do. Yet at the same time, her work also reveals the common tension held in feminist theoretical work in this area - an attachment to both constructivist approaches to knowledge that help us deconstruct gender binaries (yet risking seeing only a powerful unresolvable patriarchy everywhere), and also to empirical research into women's experiences as an antidote to male bias in knowledge production (yet risking reifying those very gender binaries again) (Prins, 1995). I have found the approaches of post-structural feminists and queer theorists more helpful in this project, whereby the multiple, overdetermined assemblages of knowledge production are examined in particular places and in particular moments with a weak theory approach (see Brown et al. 2011, Cameron and Gibson-Graham, 2003; Gibson-Graham, 2008; Sedgwick, 2003 among others). The 'weak theory' approach of Gibson-Graham was inspired in part by the second wave feminist movement and the possibilities of ubiquitous place-based activism for other causes such as ‘smashing capitalism at home in our spare time’ (Gibson-Graham, 1993, 2005).

Like other poststructural theorists, Gibson-Graham’s ethic of politics is one that values diversity and tries to start where people are 'at', in their everyday lives, to cultivate a process of resubjectification and a process of 'becoming' alternative economic activists and creating community economies (2006). Starting with what women say about their own everyday environmental work has led an Australian research team to argue that everyday sustainability work is situated in the caring labour of (often) women's domestic work, but not because women are somehow closer to nature (Organo et al., 2013; Gibson et al., 2013). Starting with what women say about their own activist work has brought to light the degree to which 'being a mother' is an important motivation for mother's environmental action in domestic and public spaces (Logsdon-Conradsen and Allred, 2010). In the same vein, I have started with what women have said about their EC and related hygiene practices, then used a weak theory approach to organise and interpret it.

\section{Key themes of direct action on OZNappyfree}

Unlike the environmental maternal activist blogs and webgroups reviewed by LogsdonConradsen and Allred (2010), the Oznappyfree women did not identify themselves — in this 
forum - as activists. Yet in forum discussions, focus groups and follow-up reflections, I have traced a number of areas of direct action for change: sustainable consumption, healthy attachment, balancing care and sharing knowledge.

\section{Theme 1: Sustainable Consumption.}

In Figure 1, I gather some representative quotes from Oznappyfree 2009 and also the more recent 2015 reflective emails where sustainable consumption is discussed. Sustainability and reduced consumption were understood as 'given', shared assumptions and motivations that rarely needed to be discussed.[5] When issues of sustainability were discussed, these were normally because new, interesting or unusual hygiene-related sustainability habits, practices or products had been discovered by members - for example, habits around hair-washing frequency or use of hair products were discussed, practices such as ‘family cloth wipes' instead of toilet paper, or products such as the menstrual cups mentioned in Figure 1. [6] The unspoken and underlying motivations for EC are multiple, but include reducing the waste of disposable nappies and likewise reducing water usage required for washing cloth nappies. This is thought to be achieved both by reducing the use of nappies on a day-to-day basis, and also significantly shortening the 'nappy career' of the child, sometimes by several years. [7]

\section{[Insert Figure 1 here]}

\section{Figure 1: Sustainable Consumption}

\section{Theme 2: Healthy attachment}

Oznappyfree mothers were eager that their children's emotional needs were met in healthy attachment parenting relationships: the underlying concern here is the role that healthy attachment (via caregiver response to nonverbal communication) plays in habituating children to empathy as a normal relational state, and thus developing empathy for others, including nonhuman others such as animals and the environment (Grille, 2008; Lewis et al., 2007).

Discussions around communication and healthy attachment were detailed and practical, but also carried a sense of parental responsibility for the decision-makers of the future - particularly around the responsibility to set up particular kinds of neural pathways for the future emotional health of society. That all members practised some form of 'attachment parenting' (Sears and Sears, 2001) was another unspoken assumption in discussion, as the forum is listed as an attachment parenting group on the Yahoo! Groups website. For some, this way of parenting fitted with their own preferences or upbringing, while for others it was a conscious ethical decision not 
just for the particular child, but also for the health of the planet and society more generally. For example, one member stated on her website "Seriously, sister, we can change the world. One birth, one child, one heart at a time”. [8] Thus the quotes in Figure 2 gather around the key theme of healthy infant communication and the meeting of infant needs, including responding to their communication around elimination (including when babies expressed a dislike of infant toileting, and seemed to prefer nappies). As illustrated in the quotes, communication was the goal rather than just reducing nappy use - direct action thus took the form of habituating an embodied twoway communicative relationship with a goal to a better world (although of course, mixed up with other motivations).

\section{[Insert Figure 2 here]}

\section{Figure 2: Healthy Attachment}

\section{Theme 3: Balancing care}

Concern for balancing the needs of those performing caring labour and other members of the family, community and planet were topics under frequent discussion. The quotes gathered in Figure 3 express both pleasure and ambivalence around EC as a practice, and address questions of time, work and gender: Does EC involve more caring labour or less for mothers? Who else does EC 'work' in the family? Is it enjoyable labour? How do you balance the demands of EC with other caring labour, and also with one's own needs? How do you set up new routines to share responsibility in family life?

Throughout 2009 and the years I have been a member of OZNappyfree , the overall tone of the group has been supportive and understanding of mothers' needs and limits. This contrasts with Bobel's (2004) analysis of 'natural parenting' as another form of 'mother-blaming'. OZNappyfree members frequently counselled each other to step back, take a break, laugh, see themselves as human beings and not super-women. 'EC fail' stories were shared as much as 'success' ones, so that new members could get realistic expectations. While some members could claim their children had never been in a disposable nappy (one even claimed her child had never been in a nappy at all), most members took the attitude that doing something towards the ideals of sustainability and healthy attachment was better than nothing at all. One member started the 'One Green Nappy’ social media campaign, encouraging users of disposables to acquire just one modern washable nappy, the environmental savings of which would add up over time. Others made efforts to document their experiences with 'part-time EC', where the caregiver only 'tunes in' to elimination communications at certain times of day, and uses nappies at other times (this 
was especially relevant for babies in childcare). Another member started a thread called 'EC is about lazy parenting' and listed all the ways EC was easier and more pleasurable than nappies. Members shared tips and tricks to make EC and parenting easier especially on difficult days, including lowering expectations of oneself in order to do a 'good enough' job. Frequently 'good enough' took the form of negotiating the line between necessity and surplus in terms of housework, children's social and learning activities, sleep, and help from others. This nuanced approach to balancing care arrangements was often situated in detailed discussions of each person's circumstances with sensitivity to their emotional state.

Due to a number of families with at-home fathers, same sex parents, or other shared-care and custody arrangements, mothers were not assumed to have to take full responsibility for EC (even if it was normally the case). Direct action was taken by a number of families to experiment with different daytime and night-time care responsibilities and habits, and to negotiate different standards of housework and domestic labour between partners. For a short period in 2009, a more 'militant' 'politics of demand' became visible in this area of self-care and infant care. After a discussion online about a proposed insurance law change that would indirectly make it illegal for Australian midwives to attend births in private homes, a number of members went on to make submissions and to picket the Australian parliament in Canberra for the right to birth at home with a trained attendant. In seeking to balance care, activism in the form of direct action (and demand) went beyond environmental concerns but extended into the feminist social issues of women’s caring labour and maternity care rights.

\section{[Insert Figure 3 here]}

\section{Figure 3: Balancing Care}

\section{Theme 4: Sharing knowledge}

The collective experience and knowledge of OZNappyfree is significant. Although this knowledge is concerning some of the most intimate and normally private bodily habits, Oznappyfree members benefit from the knowledge commons gathered on the forum website and shared by the members. Many group members were interested in communicating that shared learning and research not just within the group, but with wider audiences. One member stated her goal was to regain, preserve and share the lost knowledge of EC and went out of her way to attempt that (Figure 4). A number of members had given talks or demonstrations at local 'mum's groups', La Leche League or Australian Breastfeeding Association meet-ups, workshops and even conferences. Others had established websites or written eBooks. Others focused on how the 
habitual norms of hygiene within their family would be the starting point for their own children in the future. It was not always just EC habits that were open for sharing - sharing knowledge around other sustainable household habits was common too. While the diversity of experiences and opinions may have seemed confusing, the openness to possibilities and experimentation did lead to other direct actions in changing home habits. In 2009 for example, many members trialled washing their hair with baking soda and apple cider vinegar as an alternative to the products produced by large pharmaceutical companies with problematic environmental and business practices. Each of the 2015 reflective statements included examples of how these ideas had ongoing implications for Oznappyfree families particularly in terms of laundry practices and personal hygiene.

\section{[Insert Figure 4 here]}

\section{Figure 4: Sharing Knowledge}

Are the actions I have described under the themes of sustainable consumption, healthy attachment, balancing care and sharing knowledge forms of activism? If we think about activism as direct action for a better world, I think there is a case for understanding Oznappyfree members and EC practitioners as activists - in fact, as illustrated in this section, their environmental activism is mixed up with all kinds of activism for a better world, including habituating better balance for caregivers and mothers in particular, emotionally healthy and empathetic children becoming adults, reducing consumption of unnecessary and unsustainable products for economic as well as environmental reasons, women's rights around birth, and sharing a knowledge commons to make it easier for others wanting to adopt EC habits. Oznappyfree members fit Chatterton and Pickerill's (2010) understanding of activism as everyday practice, where everyday practice is messy, experimental, multi-layered, habitual, and contains paradoxical elements too.

But I am also interested in the ways in which the key concerns of Oznappyfree mothers’ everyday activism resonates with the key concerns Gibson-Graham, Cameron and Healy (2013) have distilled from their work examining other everyday practices of economic activism (see Table 1: Key Concerns for a Better World). In particular, sustainable consumption is directly comparable to Gibson-Graham et al.’s ‘consuming sustainably’, where they argue that people are already acting to negotiate the materials and energy they use up in the process of 'surviving well'. Gibson-Graham et al.'s concern for 'surviving well' also articulates much of what the Oznappyfree group understand to be important in their discussions around balancing their caring labour with paid labour and time for other aspects of life with an appreciation for the 'multiple 
dimensions of wellbeing that are fundamental to human flourishing' (2013, p.30). Negotiating what Gibson-Graham et al. call the 'survival-surplus nexus' (2013, p. 53), or the line between necessary and surplus labour, has been part of Oznappyfree discussions around housework - a further overlap with Gibson-Graham et al.’s key concern of ‘distributing surplus’. Using this surplus to enable not only one's own flourishing, but that of children and infants is a concern reflected in Oznappyfree discussions around infant attachment and overlaps to a degree with Gibson-Graham et al.'s key concern of 'encountering others in ways that support their wellbeing as well as ours'. Likewise, the 'investment' made in healthy infant attachment relationships correlate with Gibson-Graham et al.'s concern for 'investing our wealth in future generations', including in enabling a 'liveable future’ (2013, p. 64) for our planet and its other inhabitants. Finally, the concern for gathering and sharing knowledge about elimination communication is an example of the creation, maintenance and expansion of a 'knowledge commons' (Gibson-Graham et al., 2013, p.130), reflected in the Take Back the Economy key concern of 'caring for commons'.

[Insert Table 1 around here]

\section{Table 1: Key Concerns for a Better World}

When structured and analysed in this way, the complex, messy, direct actions for social change occurring in and around Oznappyfree forums cohere into some sort of sense. The 'what' of activism is addressed here - as the direct action is undoubtedly aimed at particular kinds of environmental and social change, such as forms of economy 'centred on ethical concerns' (Gibson-Graham et al. 2013, p. 196). I now turn to address the 'how' and the 'who' of this activism. Who is it that acts in this dispersed, unorganised (yet somehow collectivised) way? And how do these actors connect and act as a collective?

\section{Hybrid Activist Collectives}

It should have now become clearer that my intention is not to unproblematically celebrate as activist all the domestic and caring labour that women undertake in the home. As Cairns et al. (2013) and Bobel (2001, 2004) have both pointed out, the privatisation of childcare that plays out through discourses of mothering invites and perhaps pressures mother-subjects to understand themselves as individually responsible for the wellbeing of their children and family in North America. Yet this invitation is not always taken up: in regional Australia, Organo, Head and Waitt (2013) find that while women do much of the everyday sustainability and wellbeing labour in the home (making homemade washing powder and compost, feeding chickens, shopping 
decisions), men did much of the one-off 'project-based' labour (building chicken coops, establishing vegetable gardens, experimenting with recipes for bread, beer, washing powder and so on) especially if they worked longer hours of formal employment. While the labour was certainly gendered, the women in Organo et al.’s study highlighted connections to flexible and industrial time in the division of activities. Like Organo et al. I have found that action for sustainability in OZNappyfree is understood as being offered at the household level, even in cases where it is mostly mothers taking up the caring labour of EC, and certainly the emotional labour (Fraad, 2000) of researching it and engaging with the forum. Yet sustainable consumption, healthy attachment relationships, balancing care, and sharing knowledge were often reported to be household values, and OZNappyfree fathers contributed to direct action around these key concerns, both through EC and in ways other than EC (for example, promoting attachment through carrying their babies around while at home or having skin-to-skin time with newborns). The household is therefore one form of collective taking action for environmental and social change.[9]

While Organo et al.’s work helps us see the household as an actor, it only offers glimpses of moving towards larger scale collective direct action for environmental and social change. In Organo et al.’s work, these glimpses of extra-household collectivity include quotes referring to participants' use of online sources to get sustainability ideas and methods, management of a sustainability website, the sustainability competition via which the participants were recruited, and of course all kinds of collectivities incorporating the agency of the non- or more-than-human - worms, chickens, energy-efficient appliances, soil, microbes, markets and more (Organo et al., 2013). Caring labour and direct action for sustainability is thus undertaken by a broader collective than just women, or just the household. With regards to Oznappyfree, while the household is certainly one entity engaging in partially collectivised activist work, I think the main possibilities for cohering as a collective lie with the extended collective of women, babies, microbes, communications technologies and families dispersed throughout Australia and parts of New Zealand.

In imagining and describing the kind of collective who is taking action towards the variety of key concerns (described in the earlier section), I draw on the concept of a 'hybrid collective' (Callon and Rabeharisoa, 2003; Cameron, Gibson and Hill, 2014; Gibson-Graham and Roelvink, 2009; Roelvink, 2010). Gibson-Graham and Roelvink adopt the notion of the hybrid research collective in order to explain the ways in which their work has been a process of researching and 'learning together' with human and more-than-human others (2010, p. 327). Roelvink (2010) describes the way in which she, as a researcher at the World Social Forum, became part of a 
'hybrid collective creating new worlds' and 'enacting a new econo-sociality'. Roelvink describes the hybrid collective (hybrid because it includes the human and 'more-than-human', both living and inanimate) at the World Social Forum as a collective including all the participants and all that acted to make the Forum possible (technologies, tents, food markets and so on) (see Roelvink, 2010, p. 117). Gibson-Graham and Roelvink (2009) draw on STS thinking (Latour, 2004) to understand a hybrid research collective as a hybrid human/more-than-human assemblage that, through research, increases possibilities for (being in) the world.

The Oznappyfree assemblage (including myself) could be understood as the hub of a hybrid research and activist collective, taking direct action to experiment with, create, implement and share knowledge around sustainable forms of infant hygiene, and thus increase possibilities for a more sustainable and equitable world. The hybrid collective of Oznappyfree includes the mothers who directly contribute to discussions; the other associated people who do not directly contribute, including fathers, co-mothers, grandparents, older children, and childcare providers; and then, of course, the babies themselves, who communicate to the collective via idiosyncratic communications with their Oznappyfree mothers. Importantly, the collective is hybrid because it also includes all the materialities that act to enable (and at times, prevent or interrupt) these discussions and the subsequent direct actions to take place. The hybrid activist collective includes computers, tablets, mobile phones, cameras, internet infrastructure and providers, Yahoo! as forum provider, and physical infrastructure including undersea internet cabling, Wi-Fi radio waves, and other communication materialities. If we wanted to imagine a hybrid hygiene research collective specifically, we might extend the collective to be an assemblage of the all the materialities, spatialities and socialities that enable Oznappyfree collective research into hygiene. The more-than-human might also include what McKinnon (2014) refers to as the 'sub-human' in the collective: those hormonal and microbial actor-networks within the human body that (inter)act with us and each other. That somewhat unwieldy total assemblage must be put aside for now, however, as we focus on the how the hybrid collective acts for social and environmental change. The hybrid research/activist collective in this discussion will be limited to the mothers/others/babies/communication technologies.

The hybrid research/activist collective takes direct and collective action to research, experiment with, distribute and act on new knowledge of infant hygiene possibilities. This collective research, experimentation, knowledge production and direct action occurs within the sites of the body and the home in small mother-baby-microbe collectives, but occurs in conversation with far-flung parts of the larger hybrid mother/other/baby/communication technology collective. The research is reminiscent of what Callon and Rabeharisoa call 'research 
in the wild', where 'concerned groups' act as 'genuine researchers, capable of working cooperatively with professional scientists', co-producing a new forms of knowledge (2003, p. 195). In the same way that the muscular dystrophy patients studied by Callon and Rabeharisoa collectively created knowledge about their own bodies and the disease, the Oznappyfree hybrid collective has created knowledge about infant bodies and hygiene through sustained experiments with EC. In 2009, this included a regular 'monthly update' email based on a template used to track and record the progress of their EC journey. Analysis and discussion of this data was performed collectively via group email with multiple possibilities explored to explain this data. Collective knowledge-to-date was periodically summarised into posts for new members, as well as in my own research efforts made available to the group (Dombroski, 2009, 2013, 2015). All the data and analysis continues to be stored on Yahoo! servers and is available to members to this day, even as many have moved on to Facebook EC groups. The diversity of the results does not take away from the validity of this research process - in fact, it illustrates the embodied and specific nature of the knowledge created in the smaller collectives of other/baby/carers/microbes.

Through taking direct action based on these collective research 'results', the hybrid activist collective works for social and environmental change. The 'who' of the activism moves away from individuals in their homes towards a broader human and more-than-human collective taking action for change now and in the future around a set of important environmental and social concerns. The 'what' of activism moves away from demand politics to the re-forming of habits of everyday practice that, cumulatively, can make change now and more possible in the future. The 'how' of activism moves away from formal organised collectives to direct action for change via looser, hybrid activist collectives experimenting with different ways of being in and with the world in the everyday ebb and flow of life's work.

\section{Conclusion}

In this paper, I have examined the everyday activist practices of the hybrid activist collective gathered around the Oznappyfree EC discussion forum. While we should be wary of caring labour that serves to isolate women or further individualise infant, child and environmental caring responsibilities on women or mothers at the expense of our broader societal collective, we should also be taking seriously the perspectives of women making meaning of their caring labour, and find ways to theorise their lives with these meanings incorporated (Casey, 2003). While the mothers contributing to Oznappyfree did not specifically frame themselves as 'activists', the key concerns they find meaningful resonate with calls for direct ethical action to take back the economy for people and planet (Gibson-Graham, Cameron, and Healy, 2013). Drawing on the 
concept of hybrid collectives, we can understand the meaningful care-work of EC not as a burden carried by isolated individuals, but as shared research and activist work being carried out by a vibrant hybrid activist collective of mothers, babies, household members, microbes and communication technologies — researching, experimenting, documenting and sharing knowledge around the practice of elimination communication. The hybrid activist collective worked to change embodied and habituated everyday hygiene practices within the family, and these contributions to different kinds of futures should not be overlooked.

While EC has become more well-known in Australia and New Zealand, 2009 represented the peak activity of the Oznappyfree hybrid activist collective as gathered around the forum. Since that time, the growing popularity of Facebook has corresponded with a decline in new members, posts, and therefore opportunities to build collectivity and community around EC — in that forum anyway. As of December 2015 the Facebook group Elimination Communication Australia has 308 members, a proportion of which have migrated from the previous Yahoo! Group. As the hybrid activist collective has shifted and reformed with and around new technologies and social media platforms such as Facebook, Twitter, Instagram and YouTube, the key concerns may have shifted somewhat too. While Yahoo! forums tended to contain long, detailed, and personal posts about children's specific habits and needs, the relatively public space of new social media results in shorter, more photographic and less detailed posts with questions that can be answered in a few sentences. Some of the specificity and depth of discussion has therefore been lost, and perhaps the relationships that came up around those. Yet it may be that different types of hybrid activist collectives are forming, and more research into the key concerns of these emerging or shifting collectives may offer interesting developments in EC practice as well as insights for theory and activism. What this change highlights is how any theorising of those forms of activism that emerge around the everyday and habitual practices of life's work must be able to respond to shifting circumstances and technology. The shifting and fluid nature of what I am calling the 'hybrid activist collective' therefore offers potential for others theorising activism occurring without strong organisational structures, with collaboration between human and more-than-human actors. 


\section{Endnotes}

[1] 'Elimination Communication' or EC refers to the practice of communicating with a baby over its 'elimination' (urination and defecation) needs, including setting up cues and responding to nonverbal signs, in order to reduce or avoid nappy use by encouraging elimination in other appropriate places. The OZNappyfree group is open to any caregiver, but in practice the members were almost entirely mothers (only one registered as a father, but some registrations are family names and could include fathers). The active, posting members during the time of fieldwork were all mothers, although not all were the at-home parent or primary caregiver.

[2] For example in December 2009, 35 mother members contributed 100\% of the posts.

[3] The 2009 research also included two focus groups in Brisbane and Melbourne, and was approved by Australian National University Human Ethics committee. 2015 research was approved by University of Canterbury Human Ethics Committee. Permission to collect 2009 posts was given by forum administrator, who also granted access to forum usage data. Members were asked to give written consent and quotes were used from those who gave written consent. Five of these original members also wrote reflective statements in 2015.

[4] Many cultures all over the world practice a form of EC. In many parts of the world it is more normalised than in Australia or New Zealand, for example, China, South and Southeast Asia and parts of Africa. I am a

Pākēha/European New Zealander. I have lived in Australia, China and New Zealand, and have actively practiced EC with a child in each of these places.

[5] I was guided by Underhill-Sem’s (2000) work on reading silences in ethnographic fieldwork here.

[6] Menstrual cups are reusable medical-grade silicon or rubber 'cups' that are used to catch menstrual blood before it leaves the body, thus reducing or removing the need for disposable menstrual hygiene products. These cups and family cloth wipes are examples of how OZNappyfree provides a safe collective space for experiments with 'the abject' and cultural expectations hygiene. This in itself could be understood as a feminist activist stance.

[7] Although with significant parental assistance — children seem to be toileting independently only slightly earlier age than the general population, between 2 and 3 years of age.

[8] This style of 'natural' or 'attachment' parenting is sometimes (but not always) linked with an anti-consumerism ethic. The idea is that babies need relationships, not things, and families may forgo cribs, prams, infant chairs, and in this case, nappies.

[9] Using Fraad's analysis (2000) of the exploitation of 'surplus' emotional labour, there is more work to be done here in understanding the 'class processes' at play within the sustainable household, but this is beyond the scope of this paper.

\section{References}

Bauer, I. (2001), Diaper Free! The Gentle Wisdom of Natural Infant Hygiene, Natural Wisdom Press, Salt Spring Island, BC.

Blomley, N. (1994), "Editorial: Activism and the Academy”, Environment and Planning D: Society and Space, Vol. 12 No. 4, pp. 383-385.

Bobel, C. (2004), “When good enough isn't: mother blame in The Continuum Concept.” Journal of the Association for Research on Mothering, Vol. 6 No. 2, pp. 58-68. 
Bobel, C. (2001), “Bounded Liberation: A Focused Study of La Leche League International”, Gender and Society, Vol. 15 No.1, pp.130-151.

Boucke, L. (2008), Infant potty training: a gentle and primeval method adapted to modern living, White-Boucke Publishing, Lafayette, CO.

Brown, G., Browne, K., Brown, M., Roelvink, G., Carnegie, M., \& Anderson, B. (2011), “Sedgwick’s geographies: Touching space”, Progress in Human Geography, Vol. 35 No. 1, pp. 121-131.

Cairns, K., Johnston, J. and MacKendrick, N. (2013), “Feeding the 'organic child’: Mothering through ethical consumption”, Journal of Consumer Culture, Vol. 13 No. 2, pp. 97-118.

Callon, M., and Rabeharisoa, V. (2003), “ Research 'in the wild’ and the shaping of new social identities”, Technology in Society, Vol. 25, pp. 193-204.

Cameron, J., \& Gibson-Graham, J. K. (2003), “Feminising the economy: metaphors, strategies, politics”, Gender, Place and Culture, Vol. 10 No. 2, pp. 145-157.

Casey, E. (2003), ““How do you get a PhD in that?!”: using feminist epistemologies to research the lives of working class women”, International Journal of Sociology and Social Policy, Vol. 23 No. 1/2, pp. 107-123.

Chatterton, P. and Pickerill, J. (2010), “Everyday activism and transitions towards post-capitalist worlds”, Transactions of the institute of British Geographers, Vol. 35 No. 4, pp. 475-490.

Day, R. (2004), “From hegemony to affinity”, Cultural Studies, Vol. 18 No. 5, pp. 716-748.

Dombroski, K. (2010), “Poor Mothers are not Poor Mothers: Cross-cultural learning between northwest China and Australasia”, available at http://www.communityeconomies.org. (accessed 17 February 2016).

Dombroski, K. (2013), Babies’ Bottoms for a Better World: Hygiene, Modernities and Social Change in and between Northwest China and Australasia, Unpublished PhD Thesis, University of Western Sydney, Penrith, NSW.

Dombroski, K. (2015), “Multiplying Possibilities: A postdevelopment approach to hygiene and sanitation in Northwest China”, Asia Pacific Viewpoint, Vol. 56, No. 3, pp. 321-334, http://dx.doi.org/10.1111/apv.12078.

Dunn E. (2011), “The nappywars: when to toilet train?”, Sydney Morning Herald, 9 June.

Fraad, H. (2000), Exploitation in the Labor of Love. In Gibson-Graham, J.K., Resnick, S. A., and Wolff, R. D. (Eds.), Class and its Others, University of Minnesota Press, Minneapolis.

Gibson, C., Farbotko, C., Gill, N., Head, L., \& Waitt, G. (2013), Household sustainability: challenges and dilemmas in everyday life, Edward Elgar Publishing, Cheltenham. 
Gibson-Graham, J. K. (1993), “Waiting for the Revolution, or How to Smash Capitalism while Working at Home in Your Spare Time”, Rethinking Marxism, Vol.6 No.2, pp.10-24.

Gibson-Graham, J. K. (1996), The End of Capitalism (As We Knew It), University of Minnesota Press, Minneapolis.

Gibson-Graham, JK. (2005), “Building community economies: Women and the politics of place”, in Harcourt, W. and Escobar, A. (Eds), Women and the Politics of Place, Kumarian Press, Bloomfield, pp.130-157.

Gibson-Graham, J. K. (2006), A Postcapitalist Politics, University of Minnesota Press, Minneapolis.

Gibson-Graham, J.K. (2008), “Diverse economies: performative practices for other worlds”, Progress in Human Geography, Vol. 32 No. 5, pp. 613-632.

Gibson-Graham, J. K. (2011), “A feminist project of belonging for the Anthropocene”, Gender, Place \& Culture, Vol. 18 No. 1, pp. 1-21.

Gibson-Graham, J. K., Cameron, J. and Healy, S. (2013), Take Back the Economy: An ethical guide for transforming our communities, University of Minnesota Press, Minneapolis. Gibson-Graham, JK, and Roelvink, G. (2009), “An economic ethics for the Anthropocene”, Antipode, Vol. 41 No. 1, pp. 320-346.

Grille, R. (2008), Parenting for a Peaceful World, The Children's Project, Richmond. Gross-Loh, C. (2009), The Diaper-Free Baby, Harper Collins, New York. Hartocollis, A. (2013), “Baby's latest: Going diaperless”, The New York Times, 19 April. Hopgood, M.L. (2012), How Eskimos Keep Their Babies Warm: And Other Adventures in Parenting (from Argentina to Tanzania and Everywhere in Between), Algonquin Books, Chapel Hill.

Kelley, T. (2005), “A fast track to toilet training for those at the crawling stage”, The New York Times, 9 October.

Latour, B. (2004), "How to talk about the body? The normative dimension of science studies", Body and Society, Vol. 10, pp. 205-229.

Lewis, T., Amini, F., \& Lannon, R. (2007), A General Theory of Love. Vintage, New York. Logsdon-Conradsen, S.C., and Allred, S.L. (2010), "Motherhood and environmental activism: a developmental framework”, Ecopsychology,Vol. 2 No. 3, pp. 141-146.

MacGregor, S. (2006), Beyond Mothering Earth: Ecological Citizenship and the Politics of Care. UBC Press, Vancouver.

McKinnon, KI. (2014), “The Geopolitics of Birth”, Area, early view, doi: 10.1111/area.12131. Organo, V., Head, L. and Waitt, G. (2013), "Who does the work in sustainable households? A 
time and gender analysis in New South Wales, Australia”, Gender, Place and Culture, Vol. 20 No. 5, pp. 559-577.

Prins, B. (1995), “The Ethics of Hybrid Subjects: Feminist Constructivism According to Donna Haraway”, Science, Technology \& Human Values, Vol. 20 No. 3, pp. 352-367.

Roelvink, G. (2010), “Collective Action and the Politics of Affect,” Emotion, Space and Society, Vol. 3 No. 2, pp. 111-118.

Sears, W. and Sears, M. (2001), The Attachment Parenting Book: A commonsense guide to understanding and nurturing your baby, Little Brown and Company, Boston.

Sedgwick, E. K. (1997). "Paranoid reading and reparative reading, or, you're so paranoid, you probably think this introduction is about you", Novel gazing: queer readings in fiction, Duke University Press, Durham.

Sedgwick, E. (2003), Touching, Feeling: Affect, Pedagogy, Performativity, Duke University Press, Durham.

Small, M. F. (2005), “Dare to bare”, The New York Times, 11 October.

Underhill-Sem, Y. (2000), (Not) Speaking of Maternities: Pregnancy and Childbirth in Wanigela, Oro Province, Papua New Guinea, Unpublished PhD Thesis, University of Waikato, Hamilton, NZ.

Underhill-Sem, Y. (2005), "Bodies in places, places in bodies”, in Harcourt, W. and Escobar, A. (Eds.), Women and the Politics of Place, Kumarian Press, Bloomfield, CT, pp. 20-31. Whatmore, S. (2006), “Materialist returns: practising cultural geography in and for a morethan-human world”, Cultural geographies, Vol. 13, No. 4, pp. 600-609.

Whatmore, S. (2002), Hybrid geographies: Natures, cultures, spaces, Sage, Thousand Oaks. Woodford J. (2006), “It’s the bottom line: no nappies, no mess”, Sydney Morning Herald, 13 December. 